\title{
UPAYA PENINGKATAN PENDAPATAN WANITA PENGRAJIN PURUN (ELEOCHARIS DULCIS) DI KECAMATAN PERBAUNGAN
}

\author{
Wanapri Pangaribuan $^{1 *}$, Robert Silaban ${ }^{1}$ \\ Universitas Negeri Medan, Medan \\ Jl. Willem Iskandar pasar V-Kotak Pos No. 1589-Medan 20221 \\ *Penulis Korespondensi: wanapripangaribuan01@gmail.com
}

\begin{abstract}
Abstrak
Purun (Eleocharis Dulcis) adalah tanaman rumput-rumputan yang tumbuh di daerah rawa, memiliki karakteristik daya tarik dan regang yang cukup tinggi. Purun, bagi wanita suku Banjar adalah sangat erat kaitannya dengan budaya, kerajinan, dan peningkatan ekonomi keluarga. Pemanfaatan purun sebagai bahan baku tikar, tas, topi, dan berbagai wadah produk pertanian, sangat memasyarakat, sehingga memberi peluang bisnis bagi ibu-ibu rumah tangga. Sebelum dimanfaatkan dalam proses penganyaman, purun terlebih dahulu dipipihkan. Pemipihan purun, secara tradisional dengan cara meletakkan ikatan-ikatan purun di jalan raya agar digilas kenderaan dan juga dengan menumbuknya hingga pipih. Hal tersebut memperlambat produksi, dan juga purun banyak yang rusak. IbM memberi solusi dengan rancang bangun mesin pemipih purun, yang secara signifikan meningkatkan pendapatan penrajin purun tersebut. Peningkatan pendapatan wanita pengrajin purun (Eleocharis Dulcis) melalui peningkatan sikap positif terhadap peluang pasar dan pemanfaatan mesin pemipih purun berkapasitas $20 \mathrm{Kg} / \mathrm{jam}$, serta inovasi produk anyaman tikar aneka warna. Sikap wanita pengrajin purun terhadap peluang pasar yang lebih luas meningkat secara signifikan, aneka produk tikar semakin bervariasi, serta menghasilkan keuntungan produksi dalam satu minggu untuk dua kelompok dengan jumlah 31 orang meningkat dari Rp. 3. 642.500,- menjadi Rp. 4. 882.500,-.
\end{abstract}

Kata Kunci: Peningkatan pendapatan, sikap postif, pengarajin purun, mesin pemipih.

\begin{abstract}
Purun (Eleocharis Dulcis) is a plant of grass growing in the swamp area, has a high attraction and tensile characteristics. Purun, for Banjar women is very closely related to culture, craft, and economic improvement of the family. Utilization of purun as raw material of mats, bags, hats, and various containers of agricultural products, is very popular, thus providing business opportunities for housewives. Before utilized in the process of weaving, purun first flaked. Purun slaughter, traditionally by putting pentang ties on the highway to be crushed by the vehicle and also by pounding it flat. It slows down the production, and also the much-broken purun. IbM provides a solution with the design of the purun scavenger, and significantly increases the income of the purun craftsmen. Increased income of craftsmen women (Eleocharis Dulcis) through the improvement of positive attitude to market opportunities and utilization of machine enumeration purun with a capacity of 20 $\mathrm{Kg} / \mathrm{hour}$, and innovation of woven mat products of various colors. The attitude of the craftsmen women to the wider market opportunities increased significantly, the variety of mat products varied, as well profit production in one week for two groups with total 31 people increased from $R p .3$. 642.500, - to Rp. 4. 882.500, -.
\end{abstract}

Keywords: Increased revenue, positive attitude, cost reducer, fraud machine

\section{PENDAhULUAN}

Purun (eleocharis Dulcis) adalah jenis tumbuhan rumput liar yang tumbuh di dekat air atau rawa. Tanaman purun ini mudah terbakar dalam keadaan kering, terutama saat musim kemarau, menjadi salah satu pemicu kebakaran hutan. Pertumbuhan populasi purun sangat cepat sehingga pemanfaatannya memiliki peluang bisnis yang tinggi.
Tanaman purun tumbuh di daerah tropis, sehingga menjadi salah satu tumbuhan yang unik. Keunikan tumbuhan ini berada pada kekuatannya terhadap daya tarik dan kerapuhan. Meskipun tanaman yang sudah diolah mengalami perubahan musim, seperti panas terik dan hujan, dan terkena air dan terpanggang matahari, tidak menjadi rapuh dan busuk. 
Aroma harum akan terasa ketika purun kering terkena air hujan (http://tropical..).

Tanaman purun dimanfaatkan sebagai bahan baku untuk kerajinan tangan, seperti tikar, topi, wadah beras, wadah nasi, tas, dan lain sebagainya. Aneka warna dan bentuk dapat dikreasikan sehingga dapat pula dijadikan oleh-oleh atau cendra mata bagi wisatawan. Bahan baku cendra mata yang alami umumnya disukai oleh para wisatawan.

Bagi ibu rumah tangga suku Banjar khususnya, purun menjadi hal penting dalam aktivitas sehari-hari. Wanita di Desa Melati 2 Dusun 1 dan 2 Sungai Tontong Kabupaten Serdang Bedagai, Provinsi Sumatera Utara, memanfaatkan purun untuk dijadikan tikar.

Kerajinan tangan dari purun menjadi salah satu sumber pendapatan mereka. Proses pembuatan tikar membutuhkan waktu yang cukup lama, khususnya proses pemipihan purun. Pemipihan purun masih secara tradisional, yaitu dengan membentangkan purun yang sudah diikat di tengah jalan, agar digilas kenderaan. Cara lain adalah menumbuk purun secara manual atau perpaduan kedua cara tersebut. Selain lambatnya proses pemipihan juga banyak purun yang rusak dan kotor. Saat musim penghujan, maka akan terbengkalai dan tikar tidak dapat diproduksi (Pangaribuan, 2015). Sejalan dengan hal tersebut, maka solusi yang ditawarkan dan dilakukan bagi masyarakat khususnya kelompok ibu-ibu pengrajin adalah bantuan: (1) mesin pemipih purun untuk peningkatan produksi; (2) pelatihan produksi yang bervariasi; (3) manajemen produksi; (4) pengembangan sikap positif masyarakat terhadap produktivitas.

\section{KAJIAN PUSTAKA}

Akmal menemukan dalam penelitiannya bahwa terjadi produktivitas yang rendah akibat pengerjaan produksi secara manual di industri kecil kerupuk sanjai di kota Bukit Tinggi (Yori, 2006). Ismail menemukan dalam penelitiannya bahwa kelengkapan alat kerja berpengaruh positif terhadap produktivitas (Iriani, 2016). Semakin lengkap alat kerja yang dipergunakan untuk memproduksi maka semakin tinggi produktivitas. Berdasarkan kedua penelitian tersebut dapat disintesiskan bahwa kelengkapan alat kerja berpengaruh terhadap produktivitas.

Rony menemukan di dalam penelitiannya bahwa pendidikan dan pelatihan meningkatkan produktivitas[5]. Pangaribuan, dkk, menemukan perilaku inovatif mempengaruhi kinerja. Perilaku inovatif didasari oleh sikap positif, dan kinerja identik dengan produktivitas (Salinding,2011). Senada dengan itu, sikap positif mendorong seseorang untuk mengembangkan ide kreativitas yang mendukung kuantitas dan kualitas produksi (Pangaribuan, 2013).

Manajemen produksi yaitu pemanfaatan berbagai sumber daya yang memberi sumbangan positif terhadap produktivitas. Sejalan dengan hal tersebut, Matires (1998) menemukan pengaruh positif manajemen terhadap produktivitas di industri makanan dan garmen di Filippina.

Berdasarkan hasil-hasil penelitian yang telah dipaparkan dapat disimpulkan bahwa kelengkapan peralatan kerja, pelatihan, manajemen produksi, dan pengembangan sikap berpengaruh terhadap produktivitas.

\section{METODE KEGIATAN}

Tempat dan waktu kegiatan adalah di dusun 1 dan 2 Desa Melati, Kecamatan Perbaungan, Kabupaten Serdang Bedagai, Provinsi Sumatera Utara, Indonsesia pada tahun 2015. Jumlah kelompok pengrajin adalah 31 orang yang terbagi atas dua kelompok.

Metode pelaksanaan yang dipergunakan adalah pemberian pendidikan dan pelatihan dan alat berupa pemipih purun sebanyak 2 (dua) unit, yaitu masingmasing kelompok menerima 1 (satu) unit, dan juga alat-alat yang dipergunakan untuk pewarnaan purun.

Selain hal tersebut, peserta kelompok pengrajin dibimbing dalam manajemen pengolahan dan pemasaran produksi. Motivasi yang membangun sikap positif terhadap produktivitas yang dilakukan bersama-sama saat pelaksanaan pelatihan produksi.

Analisis statistik yang dipergunakan adalah analisis deskriptif. Analisis deskriptif dipergunakan untuk menganalisis sikap terhadap produktivitas, peningkatan pendapatan, dan manajemen produksi.

\section{Produksi Tikar Secara Tradisional Mitra 1}

Mitra 1 yaitu Ibu Mahani, Nama ketua pengusaha wanita pengrajin anyaman purun. Usaha tersebut merupakan usaha turun- temurun, karyawan berjumlah 4 orang.

Pengrajin membeli bahan baku purun dalam bentuk 1 bundel seharga Rp. 165.000,-, setelah itu dibersihkan dan dikeringkan kemudian diikat sehingga menjadi 20 ikatan.

Ikatan-ikatan purun kemudian diletakkan di tengah jalan agar digilas oleh setiap kenderaan yang lewat, atau dengan cara menumbuk menggunakan alat yang sangat sederhana yaitu alu dan broti sehingga purun menjadi pipih, dan setelah pipih, purun di anyam untuk dijadikan tikar. Upah untuk menumbuk purun Rp. 3.000,- /satu tikar ukuran pendek, sementara untuk ukuran panjang /satu tikar Rp. 5.000,-. Mitra, dalam 1 hari mampu memproduksi 4 tikar anyaman purun, dan produk yang dihasilkan oleh wanita pengrajin purun masih terbatas hanya dalam bentuk tikar belum ada variasi produk lainnya. Satu bundel purun dapat dijadikan sekitar 20 tikar, untuk ukuran 3 kaki, 4 kaki, 5 kaki dan 6 kaki, tergantung dari panjangnya purun. Wanita pengrajin purun di Desa Melati 2 Sungai Tontong Dusun 1, Ibu-Ibu dan remaja Putri pekerjaannya banyak yang menganyam purun tikar, untuk meningkatkan pendapatan keluarga.

\section{Mitra 2}


Mitra 2 yaitu Ibu Rasimah, Nama Usaha Wanita Pengrajin Anyaman Purun, usaha ini merupakan usaha turunan, karyawan berjumlah 3 orang. Wanita pengrajin purun Ibu Rasimah (Mitra 2), juga membeli bahan baku purun dalam bentuk 1 bundel seharga Rp. 165.000,-,

Mitra juga memproduksi tikar anyaman purun. Purun dibersihkan dan dikeringkan kemudian dibuat satu ikatan agar lebih mudah untuk digilas atau ditumbuk. Ikatan purun diletakkan di tengah jalan agar digilas oleh kenderaan yang melintas, atau dengan cara menumbuk dengan alat yang sederhana yaitu alu dan broti. Setelah pipih, purun di anyam untuk dijadikan tikar. Upah untuk menumbuk purun Rp. 3.000,-/1 tikar ukuran pendek, sementara untuk ukuran panjang /1 tikar Rp. 5.000,-. Wantu pemiphan per ikat dengan cara menumbuk sekitar 15 menit.

Wanita pengrajin anyaman purun dalam satu hari mampu memproduksi 3 - 5 tikar dan jenis produk yang dihasilkan masih terbatas hanya berbentuk tikar, belum ada variasi produk lainnya. Satu ikatan purun dapat dijadikan 20 tikar baik itu untuk ukuran 3 kaki, 4 kaki, 5 kaki dan 6 kaki tergantung dari panjangnya purun. Wanita pengrajin purun di Desa Melati 2 Sungai Tontong Dusun 2. Pekerjaan ibu dan remaja putri umumnya menganyam tikar, untuk meningkatkan pendapatan keluarga. Pemasaran produk tikar purun pada agen yang mengambil setiap hari atau 2 x seminggu; tikar purun dijual dengan harga Rp. 40.000,-/satu tikar.

Kondisi manajemen yang diterapkan oleh pengrajin anyaman purun di Mitra 1 dan Mitra 2, masih menggunakan manajemen sederhana secara kekeluargaan dimana pengelolaan administrasi yang meliputi pengaturan kerja, pembiayaan, produksi dan SDM serta penjualan hasil juga masih dilakukan secara sederhana. Pengelolaan usaha, semuanya masih dipegang oleh pimpinan Mitra 1 Ibu Mahani, Mitra 2 Ibu Rasimah, baik dalam permodalan, pengadaan bahan baku, tenaga kerja dan pemasaran.

\section{Tujuan Kegiatan Ibm Ini Adalah :}

Rancang bangun mesin pemipih purun menemukan cara atau metode untuk memproduksi variasi produk yang kreatif, dengan memanfaatkan tanaman purun. Mengingat cukup besarnya variasi dari produk anyaman purun, dan mudahnya untuk mendapatkan bahan baku purun, maka diperlukan suatu upaya untuk memberdayakan para pengrajin anyaman purun, salah satunya yaitu melalui teknologi tepat guna dan memberikan nilai seni kreatif dan inovasi produk, manajemen usaha dan pemasaran. Diharapkan pengrajin anyaman purun nantinya memiliki kuantitas dan kualitas, sehingga output yang dihasilkan dapat berkembang serta membentuk para pengrajin yang kreatif dan inovatif.

Pembekalan materi diberikan setelah Analisis acara pembukaan oleh tim pelaksana. Tujuan pembekalan materi ini adalah untuk memberikan pengetahuan dan pemahaman peserta terhadap tiga hal : (1) Teknik rancang bangun mesin pemipih purun dengan kapasitas pemipihan $20 \mathrm{~kg} / \mathrm{jam}$, (2) Penyerahan Mesin kepada ke 2 Mitra, (3) Pengetahuan tentang desain produk dan teori pewarnaan, (4) Pelatihan manajemen usaha, untuk meningkatkan keterampilan mitra dalam manajemen organisasi, produksi, keuangan, administrasi, harga, dan teknik pemasaran, (5) Analisis Sikap, (6) Analisis Ekonomis.

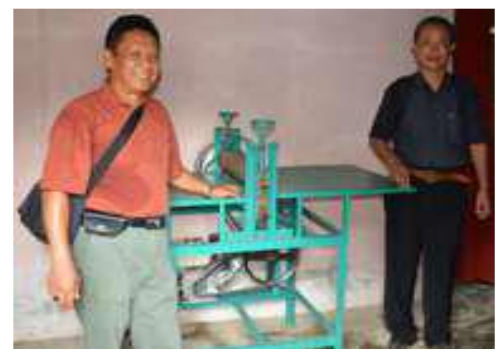

Gambar 1. Ketua dan Anggota bersama mesin pemipih purun

\section{Analisis Sikap}

Instrumen sikap wanita pengrajin purun terhadap pemberian mesin pemipih purun dan pengembangan variasi anyaman tikar dibangun berdasarkan indikator sikap yang dirumuskan oleh Bloom, yaitu: penerimaan, partisipasi, penilaian/ penentuan sikap, organisasi, dan pembentukan pola. Akan tetapi indicator instrumen hanya penerimaan, partisipasi, dan penilaian/ penentuan sikap. Instrumen berupa angket yang terdiri dari 15 butir, dengan opsi pilihan menggunakan skala Likert, yaitu : sangat setuju, setuju, tidak setuju, sangat tidak setuju. Skor tertinggi subjek analisis yang mungkin diperoleh adalah 60 dan skor terendah adalah 15. Analisis sikap menggunakan analisis deskriptif, yaitu rata-rata, median, dan modus, serta persentase.

\section{Analisis Ekonomi}

Analisis ekonomi meliputi perbandingan waktu proses produksi, jumlah produksi, jumlah pendapatan dan keuntungan sebelum dan setelah menggunakan mesin pemipih purun serta pendidikan dan pelatihan diberikan. Analisis dilakukan secara sederhana.

\section{HASIL DAN PEMBAHASAN \\ Hasil Kegiatan \\ Sikap Positif terhadap Produktivitas}

Hasil analisis data memperlihatkan nilai ratarata skor sikap adalah 48,81; median adalah 48; dan modus adalah 49. Berdasarkan hal tersebut, maka dapat disimpulkan sikap ibu pengrajin purun terhadap produktivitas adalah baik.

\section{Kinerja Waktu Mesin Pemipih Purun}

Hasil dari kegiatan program IbM ini yaitu satu buah mesin pemipih purun dengan kapasitas 20 $\mathrm{Kg} / \mathrm{jam}$. Mesin pemipih purun dilengkapi motor penggerak mula berupa mesin disel. Efesiensi mesin cukup tinggi sehingga dapat menghasilkan keuntungan produksi secara kuantitatif dan kualitatif. 
Penganyaman 1 tikar ukuran 1,5 m x $3 \mathrm{~m}$ dibutuhkan waktu 6 jam penuh.

Perbandingan kinerja pemipihan purun dengan cara digilas, ditumbuk dan dimesin, yang ditinjau dari waktu diperlihatkan pada tabel 1 berikut.

Tabel 1. Perbandingan waktu produksi

\begin{tabular}{|l|c|c|c|}
\hline $\begin{array}{c}\text { Nama } \\
\text { Metode }\end{array}$ & $\begin{array}{c}\text { Waktu } \\
\text { proses } \\
\text { (menit) }\end{array}$ & $\begin{array}{c}\text { Jumlah ikatan } \\
\text { pipihan purun } \\
\text { (per 45 } \\
\text { menit) }\end{array}$ & $\begin{array}{c}\text { Produk- } \\
\text { tivitas } \\
\text { mesin }\end{array}$ \\
\hline $\begin{array}{l}\text { Digilas } \\
\text { kenderaan }\end{array}$ & 450 & 1 ikat $(5 \mathrm{Kg})$ & - \\
\hline Ditumbuk & 135 & $\begin{array}{c}3,33 \mathrm{ikat} \\
(16,66 \mathrm{Kg})\end{array}$ & - \\
\hline dimesin & 15 & $\begin{array}{c}30 \mathrm{ikat}(150 \\
\mathrm{Kg})\end{array}$ & $\begin{array}{c}4 \mathrm{ikat} / \mathrm{jam} \\
(20 \mathrm{Kg} / \mathrm{jam})\end{array}$ \\
\hline
\end{tabular}

Berdasarkan tabel 1 tersebut dapat dilihat, perbedaan yang sangat signifikan waktu yang dibutuhkan untuk pemipihan purun dari ketiga cara tersebut. Produktivitas mesin pemipih purun adalah sebesar $4 \mathrm{ikat} / \mathrm{jam}$ atau $20 \mathrm{~kg} / \mathrm{jam}$.

\section{Kinerja Ekonomi Mesin Pemipih Purun}

Upah menumbuk purun satu ikat (5kg) Rp. 5000,- atau Rp. 1000,-/Kg. Harga bahan bakar bensin Rp. 7500,-/liter; dan bahan bakar bensin satu liter dapat memipihkan purun sebanyak $40 \mathrm{Kg}$. Sejalan dengan hal tersebut, maka biaya pemipihan purun $/ \mathrm{Kg}$ dengan mesin sekitar Rp. 200,-/Kg. Sejalan dengan hal tersebut, maka perbandingan produktivitas secara ekonomi dalam pemipihan purun adalah 5:1:0,2 atau 25:5:1. Artinya, secara mesin bernilai 25, secara tumbukan bernilai 5, dan secara gilasan bernilai 1 . Sejalan dengan hal tersebut ada perbedaan yang signifikan biaya proses pemipihan dengan menggilas, menumbuk, dan memesin.

Tabel 2. Perbandingan Ongkos Produksi untuk 450 menit.

\begin{tabular}{|l|c|c|c|c|}
\hline $\begin{array}{c}\text { Nama } \\
\text { Metode }\end{array}$ & $\begin{array}{c}\text { Harga } \\
\text { Purun/ } \\
\mathrm{Kg}\end{array}$ & $\begin{array}{c}\text { Ongkos } \\
\text { pemipih } \\
\text { an } \\
/ \mathrm{Kg}\end{array}$ & $\begin{array}{c}\text { Ongkos } \\
\text { pengany } \\
\text { aman } \\
\text { tikar } \\
(1,5 \mathrm{~m} \mathrm{x} \\
3 \mathrm{~m}\end{array}$ & $\begin{array}{c}\text { Ongkos } \\
\text { Produksi } \\
\text { Tikar } \\
(1,5 \mathrm{~m} \mathrm{x} \\
3 \mathrm{~m})\end{array}$ \\
\hline $\begin{array}{l}\text { Digilas } \\
\text { kendera } \\
\text { an }\end{array}$ & 1.650 & 1.000 & 20.000 & 28.250 \\
\hline $\begin{array}{l}\text { Ditumb } \\
\text { uk }\end{array}$ & $\mathrm{Rp}$. & $\mathrm{Rp}$. & $\mathrm{Rp}$. & $\mathrm{Rp}$. \\
\hline $\begin{array}{l}\text { Dimesi } \\
\mathrm{n}\end{array}$ & 1.650 & 1.000 & 20.000 & 28.250 \\
\hline
\end{tabular}

Berdasarkan tabel 2 dapat diketahui ada perbedaan Rp. 4.000,- ongkos produksi setiap tikar ukuran 1,5 m x $4 \mathrm{~m}$. Perbedaan

Ongkos produksi tersebut cukup besar, apa lagi jika produksi per minggu atau per bulan. Perbedaan tersebut sudah sangat signifikan. Produktivitas seorang ibu/hari dalam memproduksi tikar ukuran 1,5 $\mathrm{m} \times 3 \mathrm{~m}$ dapat dilihat pada tabel 3 berikut.

Tabel 3. Perbandingan Waktu Produksi per tikar ukuran $1,5 \mathrm{~m}$ x $3 \mathrm{~m}$

\begin{tabular}{|l|c|c|c|}
\hline \multicolumn{1}{|c|}{ Jenis } & $\begin{array}{c}\text { Waktu } \\
\text { pemi- } \\
\text { pihan } \\
\text { (menit) }\end{array}$ & $\begin{array}{c}\text { Waktu } \\
\text { penga- } \\
\text { nyaman } \\
\text { (menit) }\end{array}$ & $\begin{array}{c}\text { Waktu } \\
\text { Produksi satu } \\
\text { tikar (menit) }\end{array}$ \\
\hline $\begin{array}{l}\text { Digilas } \\
\text { Kenderaan }\end{array}$ & 450 & 3600 & 4050 \\
\hline Ditumbuk & 135 & 3600 & 3735 \\
\hline Dimesin & 15 & 3600 & 3615 \\
\hline
\end{tabular}

Berdasarkan tabel 3 dapat diketahui, perbedaan waktu produksi dengan ketiga metode adalah waktu pemipihan. Hal tersebut mengakibatkan waktu produksi untuk satu tikar ukuran 1,5 m x $3 \mathrm{~m}$ dengan metode pemipihan penggilasan kenderaan adalah 4.050 menit, sedangkan dengan ditumbuk adalah 3735 menit, dan dengan mesin hanya 3615 menit.

Seorang ibu pengrajin dapat memproduksi tikar dalam satu minggu dengan keuntungan. Jika dibandingkan dengan ketiga metode tersebut, maka ada perbedaan yang signifikan, sebagai mana diperlihatkan pada tabel 4. Keuntungan setiap 10 lembar tikar, dengan metode menggilas dan menumbuk sebesar Rp. 117.500,-, sedangkan dengan metode mesin sebesar Rp. 157.500,-. Jika dihitung keuntungan per kelompok per minggu untuk metode menggilas dan menumbuk sebesar Rp. 3.642.500,-, sedangkan dengan metode mesin sebesar Rp. 4.882.500,-. Berdasarkan analisis tersebut, perbedaannya signifikan.

Tabel 4. Perbandingan Keuntungan penjualan tikar per orang dan per kelompok dalam satu minggu

\begin{tabular}{|c|c|c|c|c|}
\hline $\begin{array}{c}\text { Jenis } \\
\text { Metode }\end{array}$ & $\begin{array}{c}\text { Ongkos } \\
\text { produk } \\
\text { si per } \\
10 \\
\text { lembar }\end{array}$ & $\begin{array}{c}\text { Penjual } \\
\text { an } 10 \\
\text { lembar }\end{array}$ & $\begin{array}{c}\text { Keuntun } \\
\text { gan dari } \\
10 \\
\text { lembar }\end{array}$ & $\begin{array}{c}\text { Keuntun } \\
\text { gan } \\
\text { kelompo } \\
\text { k } \\
(31 \\
\text { orang) }\end{array}$ \\
\hline $\begin{array}{l}\text { Penggil } \\
\text { asan }\end{array}$ & $\begin{array}{c}\text { Rp. } \\
28.250\end{array}$ & $\begin{array}{c}\mathrm{Rp} \\
400.00 \\
0\end{array}$ & $\begin{array}{c}\text { Rp. } \\
117.500\end{array}$ & $\begin{array}{c}\text { Rp. } \\
3.642 .50 \\
0\end{array}$ \\
\hline $\begin{array}{l}\text { Penumb } \\
\text { ukan }\end{array}$ & $\begin{array}{c}\text { Rp. } \\
28.250\end{array}$ & $\begin{array}{c}\text { Rp.400 } \\
.000\end{array}$ & $\begin{array}{c}\text { Rp. } \\
117.500\end{array}$ & $\begin{array}{c}\text { Rp. } \\
3.642 .50 \\
0\end{array}$ \\
\hline $\begin{array}{l}\text { Pemesin } \\
\text { an }\end{array}$ & $\begin{array}{c}\text { Rp. } \\
24.250\end{array}$ & $\begin{array}{c}\text { Rp.400 } \\
.000\end{array}$ & $\begin{array}{c}\text { Rp. } \\
157.500\end{array}$ & $\begin{array}{c}\text { Rp. } \\
4.882 .50 \\
0\end{array}$ \\
\hline
\end{tabular}

Variasi tikar yang diproduksi sebelumnya tidak ada ditinjau dari segi warna, akan tetapi setelah diberikan pelatihan pewarnaan, maka produksi tikar sudah Warna-warni. Keuntungan penjualan tikar dengan warna warni tidak jauh berbeda, karena lama penganyaman akan bertambah. 


\section{Pendidikan Dan Pelatihan Manajemen}

Pendidikan manajemen yang dilaksanakan meliputi, manajemen waktu produksi, manajemen penyediaan bahan baku, manajemen proses produksi, manajemen keuangan dan pengembangan usaha.

Manajemen waktu bertujuan menyeimbangkan penggunaan waktu untuk produksi dengan keluarga. Keseimbangan tersebut akan memberi kesejahteraan keluarga, karena keluarga tidak diterlantarkan. Manajemen bahan baku perlu dilakukan untuk keberlangsungan produksi. Sejalan dengan hal tersebut, pemanenan purun dan pembelian purun harus dipertimbangkan, sehingga stok bahan baku tersedia selalu untuk proses produksi.

Manajemen proses produksi bertujuan untuk menghasilkan kualitas produk yang tinggi. Wanita pengrajin yang memiliki keterampilan yang lebih baik dari yang lainnya harus member arahan dan bimbingan kepada rekannya sehingga kualitas dapat tercapai. Selain hal tersebut, ada perbedaan waktu dari masing-masing individu dalam memproduksi tikar, namun dengan manajemen tersebut dibangun rasa kebersamaan sehingga perbedaan tersebut tidak dipermasalahkan.

Manajemen keuangan perlu dilakukan agar usaha dapat berkembang. Keuangan dibagi atas lima bagian, yaitu modal bahan baku, modal pemeliharaan, modal produksi dan pemasaran, modal pengembangan usaha, dan peruntukan upah anggota. Upah anggota yang menjadi hal anggota kelompok untuk dipergunakan dalam kebutuhan keluarga.

\section{KESIMPULAN DAN SARAN}

\section{Kesimpulan}

1. Sikap ibu pengrajin purun terhadap Produktivitas adalah baik.

2. Produktivitas mesin pemipih purun yang dirancang adalah $20 \mathrm{Kg} / \mathrm{jam}$.

3. Keuntungan produksi per orang dalam satu minggu (10 unit) tikar ukuran $1,5 \mathrm{~m}$ x $3 \mathrm{~m}$ meningkat dari Rp. 117.500,- menjadi Rp. $157.500,-$.

4. Keuntungan produksi kelompok dalam satu minggu (31 orang) adalah meningkat dari Rp. 3.642,500,- menjadi Rp. 4.882.500,-.

5. Pendidikan manajemen yang meliputi manajemen waktu produksi, manajemen penyediaan bahan baku, manajemen proses produksi, manajemen keuangan dan pengembangan usaha, adalah berhasil.

\section{Saran}

Melalui kegiatan Program IbM ini, diharapkan pengrajin anyaman purun lebih meningkatkan nilai kreativitas dari produk anyaman purun, karena kerajinan tangan dari purun ini menjadi salah satu sumber penghasilan Mitra dan masyarakat. Kreativitas produksi yang diharapkan adalah tikar warna-warni, topi nelayan dan topi pelancong, tas dengan berbagai variasi ukuran dan model, kantong wadah berbagai benda kecil-kecil, tlapak meja dengan berbagai lukisan alam, dan lain sebagainya.

Kerajinan purun memiliki peluang di pasar domestik maupun pasar ekspor. Hasil

produksinya cukup bagus, relatif murah, multi fungsi dan tahan lama.

Manajemen yang telah dibelajarkan hendaknya semakin berkembang, sehingga ikatan kelompok pengrajin diharapkan tetap kokoh/kuat, bahkan diharapkan muncul kelompok-kelompok yang baru hasil binaan kelompok lama. Perkembangan kelompok ini dapat menjadikan desa yang semakin maju.

Keberlanjutan usaha pengrajin purun. diharapkan dapat terjamin melalui keterlibatan kepala desa dan perangkatnya, terutama dalam koordinir pelaksanaan produksi oleh pengarajin. Tidak hanya itu saja, akan tetapi pengembangan usaha dan kelompok yang lebih banyak hendaknya dibangun sehingga harapannya ke depan menjadi produk usaha yang di eksport ke luar negeri.

Perluasan usaha kerajinan purun hendaknya dilakukan oleh pemerintah di berbagai desa atau kecamatan di seluruh provinsi. Perluasan tersebut melalui pembudidayaan purun dan produktivitas serta variasi berbagai bentuk dan kebutuhan kerajinan purun.

\section{DAFTAR PUSTAKA}

Akmal Yori. 2006. Analisis Faktor-faktor yang Mempengaruhi Produktivitas Tenaga Kerja Industri Kecil Kerupuk Sanjai di Kota Bukittinggi . Skripsi. Bogor: Program Studi Ekonomi Pertanian dan Sumber Daya Fakultas Pertanian Institut Pertanian Bogor.

http://tropical.theferns. info/ viewtropical.php? id= Eleocharis+dulciss

Ismail Iriani. Pengaruh Kelengkapan Alat Kerja Dan Disiplin Kerja Terhadap Kinerja Karyawan (Studi Kasus pada Karyawan Lapangan PT. PLN persero Pamekasan). Jurnal Studi Manajemen Dan Bisnis Vol. 3 No. 1 Tahun 2016.

Martires R. Conception. Management and Its Impact on Productivity In The Philipine Work Setting of Food and Garment Indutries. Philippine Review of Economic and Business. Vol. 25, No. 3,4, September, Desember 1988.

Pangaribuan Wanapri. 2015. Hasil wawancara dengan masyarakat pegrajin

Pangaribuan Wanapri, Siburian Paningkat, Manullang Jongga. Determining Factors of Senior High School Principals' Performance in Medan North Sumatera Indonesia. International Journal of Sciences: Basic and Applied Research (IJSBAR) (2016) Volume 25, No 2, pp 44-57 
Pangaribuan Wanapri. Membangun Ide dan Gagasan Ilniah Bernilai Jual. Generasi kampus, Vol. 6 No. 1. April, 2013. Unimed.

Salinding Rony. 2011. Analisis Pengaruh Pelatihan terhadap Produktivitas Kerja Karyawan pada PT. Erajaya Swasembada Cabang Makassar. Sripsi. Makassar: Universitas Hasanuddin.

(Terima kasih diucapkan kepada Universitas Negeri Medan dan Kementerian Riset Teknologi dan Pendidikan Tinggi, Direktorat Jenderal Pembelajaran dan Kemahasiswaan, Direktorat Riset dan Pengabdian kepada Masyarakat, yang telah membiayai kegiatan, sesuai Surat Perjanjian Pelaksanaan Hibah Pengabdian Kepada Masyarakat No. 051/ SP2H/PPM/ DIT. LITABMAS/II/2015, tanggal 15 Februari 2017). 